\title{
Persistent cauda equina syndrome after caudal epidural injection under severe spinal stenosis: a case report
}

\author{
Young Tak Seo' \\ Hyun Ho Kong' \\ Goo Joo Lee' \\ Heui Je Bang ${ }^{1,2}$ \\ 'Department of Rehabilitation \\ Medicine, Chungbuk National \\ University Hospital, ${ }^{2}$ Department \\ of Rehabilitation Medicine, College \\ of Medicine, Chungbuk National \\ University, Cheongju, Republic \\ of Korea
}

\author{
This article was published in the following Dove Press journal: \\ Journal of Pain Research \\ 12 June 2017 \\ Number of times this article has been viewed
}

Correspondence: Heui Je Bang Department of Rehabilitation Medicine, College of Medicine, Chungbuk National University, Chungdae-ro I, Seowon-Gu, Cheongju, Chungcheongbuk-do 28644, Republic of Korea

Tel +82432696227

Fax +82432696228

Email bang@chungbuk.ac.kr

\begin{abstract}
Caudal epidural injection (CEI) is one of the most common treatments for low-back pain with sciatica. CEI rarely leads to neurologic complications. We report a case of persistent cauda equina syndrome after CEI. A 44-year-old male patient with severe L4 and L5 spinal stenosis underwent CEI for low-back pain and sciatica. The CEI solution consisted of bupivacaine, hyaluronidase, triamcinolone acetonide, and normal saline. He experienced motor weakness and sensory loss in both lower extremities and neurogenic bladder for more than 1 year after the procedure. His ankle dorsiflexors, big-toe extensors, and ankle plantar flexors on both sides were checked and categorized as motor-power Medical Research Council grade 0 . His bilateral ankle-jerk reflection was absent. An electrophysiological study showed lumbosacral polyradiculopathy affecting both sides of the L5 and S1 nerve roots. A urodynamic study revealed hypoactive neurogenic bladder affecting both sacral roots.
\end{abstract}

Keywords: epidural injection, cauda equina syndrome, complications

\section{Introduction}

The prevalence rate of low-back pain over a lifetime is $39 \% .{ }^{1}$ Nonsurgical treatments for low-back pain are pharmacological, such as nonsteroidal anti-inflammatory drugs, physical therapy, or epidural injections. ${ }^{2}$ Epidural injections have been widely used to treat low-back pain with sciatica. ${ }^{3}$ There are the ways to approach the lumbar epidural space: transforaminal, interlaminar, and caudal. ${ }^{4}$ Epidural injection is safe, but sometimes leads to serious neurological complications from intravascular injection, direct needle injury, or nerve damage, such as cauda equina syndrome (CES). ${ }^{2} \mathrm{Cau}-$ dal epidural injection (CEI) is easier than transforaminal and interlaminar epidural injection for entering the epidural space, and has minimal risk of dural puncture. ${ }^{5}$ The disadvantages of CEI are unreliable spread of local anesthetics ${ }^{6}$ and inaccurate placement of the needle. ${ }^{7}$

Some studies ${ }^{8,9}$ have shown that transforaminal or interlaminar epidural injection can cause CES. Complications, such as transient paraplegia ${ }^{10}$ and arachnoiditis, ${ }^{11}$ have been reported after CEI, but we could not find any case reports on severe persistent CES after CEI. Here, we report the case of a patient with spinal stenosis suffering severe persistent CES after CEI.

\section{Case report}

A 44-year-old male patient visited the primary hospital for continuing low-back pain with radiation to the left lower extremity for 2 months. There was no trauma history 
or neurologic deficit before the visit. Low-back pain with sciatica was aggravated when walking, even standing, and relieved when he was lying down. A severe spinal stenosis and central disc extrusion at L4-L5 were observed in the lumbar spinal computerized tomography (Figure 1). The CEI was done using a 23-gauge syringe needle without fluoroscopic guidance in the primary hospital. The tip of the needle was advanced no further than S3 to avoid the risk of dural puncture during procedure. The physician used an injection solution with $4 \mathrm{~mL} 0.25 \%$ bupivacaine (Myungmoon Pharm Co., Seoul, Republic of Korea), $2 \mathrm{~mL}$ hyaluronidase (Guju Pharma, Seoul, Republic of Korea), $20 \mathrm{mg}$ triamcinolone (Kukje Pharma, Gyeonggi-do, Republic of Korea), and $8.5 \mathrm{~mL}$ normal saline. The local anesthetics

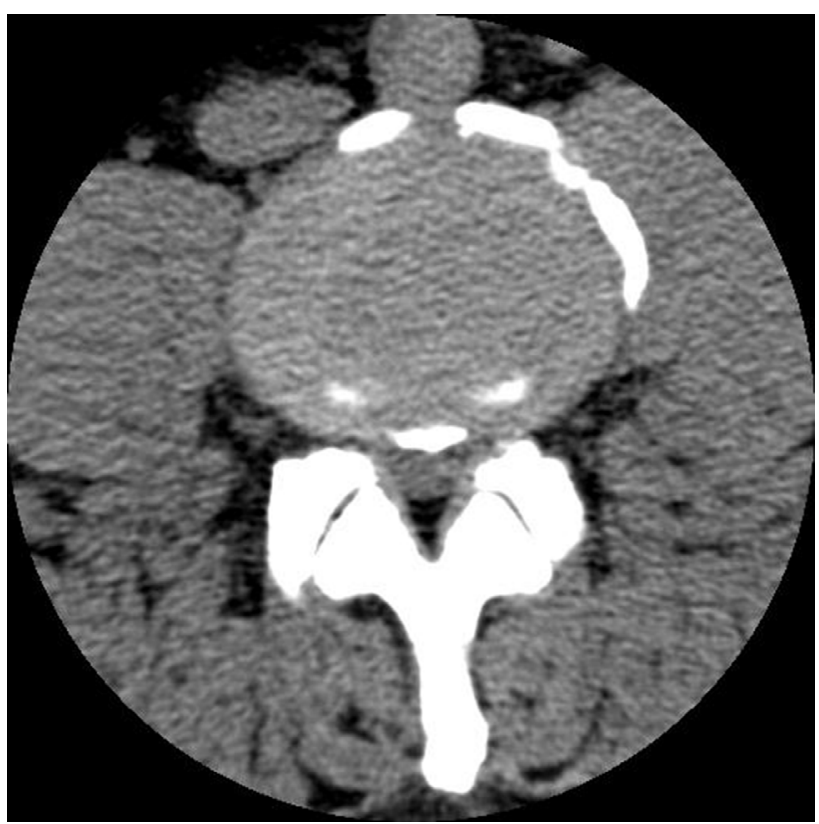

Figure I Computerized tomography of the lumbosacral spine.

Note: L4-L5 axial image reveals central disc extrusion with inferior migration at L4-L5 and severe central canal stenosis. were preservative-free. Two hours after the injection, the patient suffered severe pain like a tingling sensation in both legs and at the injection site when changing position and motor weakness in both lower limbs. Twelve hours after the injection, an indwelling catheter was inserted because of voiding difficulty. The neurologic deficits had not improved 20 hours after the injection, and the patient was thus transferred to the tertiary hospital.

A physical examination in the emergency room revealed decreased sensations below both L5 dermatome with bilateral knee-flexor motor-power Medical Research Council (MRC) grade 3 , hip extensors 1 , ankle dorsiflexors 0 , big-toe extensors 0 , and ankle plantar flexors 0 with stable vital signs. The bilateral ankle deep-tendon reflex was absent. Central disc extrusion with inferior migration at L4-L5 and severe spinal stenosis were observed in lumbosacral spine magnetic resonance imaging (MRI) performed in the emergency room (Figure 2). There was no specific evidence of infection or traumatic hematoma in the MRI. There was no active lesion on chest X-ray. The white blood-cell count and C-reactive proteins were within normal limits. At 24 hours after the neurologic deficits appeared, the patient underwent L4-S1 posterior decompression and fixation, due to suspected CES. We did not detect any improvement in neurological deficits after the operation. An electrophysiological study performed 1 month after the operation showed acute significant lumbosacral polyradiculopathy affecting the L5 and S1 nerve roots on both sides. Although the findings of a sensory nerve-conduction study on both superficial peroneal and sural nerves were within normal ranges, compound muscle action potentials on both the peroneal and right posterior tibial nerves were not elicited. The amplitude of the potentials on the left posterior tibial nerve was decreased (Table 1). Neither H-reflex was elicited. Needle electromyography showed abnormal spontaneous activities in most of the myotomes from L5 to

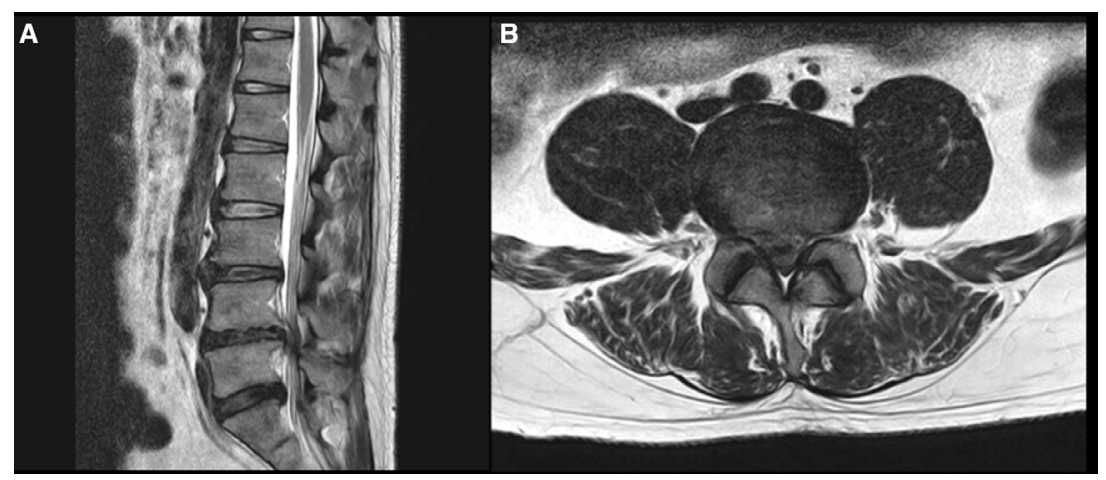

Figure 2 Magnetic resonance $T_{2}$-weighted imaging of the lumbosacral spine.

Notes: Sagittal $T_{2}$-weighted image (A) and axial $T_{2}$-weighted image (B) reveal L4-L5 severe central canal stenosis. 
Table I Nerve-conduction study results

\begin{tabular}{|c|c|c|c|c|c|c|}
\hline \multirow{2}{*}{$\begin{array}{l}\text { Nerve conduction } \\
\text { study }\end{array}$} & \multicolumn{3}{|l|}{ Right } & \multicolumn{3}{|l|}{ Left } \\
\hline & DL (ms) & $\operatorname{Amp}(\mathrm{mV})$ & $\mathrm{CV}(\mathrm{m} / \mathrm{s})$ & DL (ms) & $\operatorname{Amp}(\mathrm{mV})$ & $\mathrm{CV}(\mathrm{m} / \mathrm{s})$ \\
\hline \multicolumn{7}{|c|}{ Compound muscle action potential } \\
\hline Peroneal & No response & No response & No response & No response & No response & No response \\
\hline Tibial & No response & No response & No response & $6.00^{\#}$ & $0.5^{*}$ & 43.8 \\
\hline \multicolumn{7}{|c|}{ Sensory nerve action potential } \\
\hline Superficial peroneal & 3.05 & 7.3 & & 3.05 & 6.1 & \\
\hline Sural & 2.50 & 10.8 & & 2.75 & 9.5 & \\
\hline
\end{tabular}

Notes: "Delayed distal latency; *decreased amplitude.

Abbreviations: DL, distal latency; Amp, amplitude; CV, conduction velocity.

Table 2 Needle electromyography results

\begin{tabular}{|c|c|c|c|c|c|}
\hline \multicolumn{6}{|l|}{ Muscle } \\
\hline \multirow{2}{*}{ Right } & \multicolumn{3}{|l|}{ SA } & \multirow[t]{2}{*}{ MU } & \multirow[t]{2}{*}{$\operatorname{Rec}$} \\
\hline & IA & Fib & PSW & & \\
\hline Vastus medialis & Normal & None & None & NMU & C \\
\hline Tibialis anterior & Normal & $2+$ & $2+$ & NMU & $\mathrm{D}$ \\
\hline Peroneus longus & Normal & $2+$ & $2+$ & NMU & $S$ \\
\hline Tensor fascia lata & Normal & $\mathrm{I}+$ & I+ & - & - \\
\hline Gastrocnemius (lateral) & Normal & $\mathrm{I}+$ & $\mathrm{I}+$ & - & - \\
\hline Gastrocnemius (medial) & Normal & $2+$ & $2+$ & NMU & $S$ \\
\hline Biceps femoris (short head) & Normal & $\mathrm{I}+$ & $\mathrm{I}+$ & NMU & $S$ \\
\hline Semitendinosus & Normal & None & None & NMU & $\mathrm{D}$ \\
\hline Rectus femoris & Normal & None & None & NMU & C \\
\hline Lower lumbar paraspinal & Normal & $3+$ & $3+$ & & \\
\hline \multirow{2}{*}{ Left } & \multicolumn{3}{|l|}{ SA } & \multirow{2}{*}{ MU } & \multirow{2}{*}{$\operatorname{Rec}$} \\
\hline & IA & Fib & PSW & & \\
\hline Vastus medialis & Normal & None & None & NMU & C \\
\hline Tibialis anterior & Normal & $2+$ & $2+$ & NMU & $\mathrm{D}$ \\
\hline Peroneus longus & Normal & $2+$ & $2+$ & NMU & $\mathrm{S}$ \\
\hline Tensor fascia lata & Normal & $\mathrm{I}+$ & $\mathrm{I}+$ & - & - \\
\hline Gastrocnemius (lateral) & Normal & $\mathrm{I}+$ & I+ & NMU & $S$ \\
\hline Gastrocnemius (medial) & Normal & $2+$ & $2+$ & NMU & $S$ \\
\hline Biceps femoris (short head) & Normal & None & None & NMU & $S$ \\
\hline Semitendinosus & Normal & $2+$ & $2+$ & NMU & $\mathrm{D}$ \\
\hline Rectus femoris & Normal & None & None & NMU & C \\
\hline Lower lumbar paraspinal & Normal & $2+$ & $2+$ & & \\
\hline
\end{tabular}

Note: -, no motor unit.

Abbreviations: SA, spontaneous activity; IA, insertional activity; Fib, fibrillation potential; PSW, positive sharp wave; MU, motor unit; Rec, recruitment pattern; NMU, normal motor unit; S, single; D, discrete; C, complete.

S1 on both sides. Also, no motor-unit action potential was observed or recruitment found decreased on the L5 and S1 myotomes (Table 2). A urodynamic study performed 4 weeks after the operation showed decreased bladder sensation during the filling phase and decreased detrusor activity during the voiding phase. When checking a gadolinium MRI that was conducted after 2 months of neurologic symptoms, we could not find any lesions causing CES. One year after the paraplegia, there was a little improvement in both ankle dorsiflexors and plantar flexors motor power, which were MRC grade 2. There was also some improvement in both hip extensors' motor power, which were MRC grade 3. However, there was no improvement in a nerve-conduction study. The patient was able to void by himself with Credé's maneuver. The patient could walk using a walker with both ankle and foot orthosis.

\section{Discussion}

Epidural steroid injection (ESI) inhibits the synthesis of prostaglandins, causing inflammation and ectopic discharge from a sensory nerve that is injured. ${ }^{12,13}$ The advantage of ESI is that it is a minimally invasive treatment for patients with lumbar pain. ${ }^{14}$ ESI also has a more favorable risk-benefit profile than other treatments, such as medication, physical therapy, or surgery, and has a better cost-benefit profile than surgery. ${ }^{4}$ However, Kane ${ }^{15}$ and Moen et $\mathrm{al}^{16}$ reported that serious neurologic complications occurred in three cases per 50,000 epidural injections and 32 cases per 450,000 epidural injections. This shows that significant neurologic complications after epidural injection are rare, but can result from the injection solution, mechanical ischemia, direct needle injury, or infection. ${ }^{2}$

Complications after CEI include insomnia the night of the injection, transient nonpositional headaches that resolve within 24 hours, increased back pain, facial flushing, vasovagal reactions, episodes of nausea, and increased leg pain. ${ }^{17}$ Among these, severe neurologic complications rarely occur. Kim and $\mathrm{Kim}^{10}$ reported a paraplegia case with neurogenic bladder and bowel that occurred when $0.25 \%$ bupivacaine $10 \mathrm{~mL}$ and triamcinolone $40 \mathrm{mg}$ were injected during CEI. The patient recovered fully within 4 weeks. Somanchi et $\mathrm{a}^{18}$ reported a case of CEI with a $0.5 \%$ bupivacaine and $20 \mathrm{mg}$ triamcinolone dose that caused neurotoxicity. The patient recovered fully within 8 hours. Lee et al ${ }^{19}$ reported a paraplegia case caused by an air-acceptance test during CEI. The patient recovered fully within 7 hours. Nanjayan et $\mathrm{al}^{11}$ reported arachnoiditis after CEI using $7 \mathrm{~mL} \mathrm{1 \%}$ lidocaine, $80 \mathrm{mg}$ triamcinolone, and $7 \mathrm{~mL}$ normal saline. The patient 
recovered within 2 weeks of the procedure. However, in our case study, severe neurologic complications persisted over 1 year after CEI using a mixture of $4 \mathrm{~mL} 0.25 \%$ bupivacaine, $2 \mathrm{~mL}$ hyaluronidase, $20 \mathrm{mg}$ of triamcinolone, and $8.5 \mathrm{~mL}$ normal saline.

We considered two possibilities for the cause of CES in our case. First, there is a possibility of drug-induced neurotoxicity, which is especially caused by local anesthetics. Several studies have reported neurologic complications after transforaminal or interlaminar epidural injection. Huntoon and Martin $^{8}$ reported CES after an L2-level transforaminal epidural injection using $0.125 \%$ bupivacaine and $40 \mathrm{mg}$ triamcinolone. Kennedy et $\mathrm{al}^{20}$ reported CES after an L3-L4 transforaminal epidural injection using $0.75 \%$ bupivacaine. Also, $0.5 \%$ hyperbaric bupivacaine, ${ }^{21} 2 \%$ lidocaine, ${ }^{22}$ and $5 \%$ lidocaine ${ }^{23}$ have been reported. Drasner et $\mathrm{al}^{24}$ reported CES after an epidural injection solution using 5\% lidocaine entered the subarachnoid space accidentally. Because there was no dural puncture or outflow of cerebrospinal fluid during CEI in our case, the direct entrance of local anesthetics to the subarachnoid space during injection can be ruled out. However, because of the absent epineurium of cauda equina, even a low concentration of local anesthetic may induce neurotoxicity. ${ }^{25}$ While the $4 \mathrm{~mL} 0.25 \%$ bupivacaine used in our case might be a safe dose and concentration, we could not rule out local anesthetic-induced neurotoxicity.

The use of ESI is very common in many countries. Lenoir et $\mathrm{al}^{26}$ reported CES after an L3-L4 interlaminar epidural injection using $125 \mathrm{mg}$ hydrocortancyl. Bilir and Gulec $^{22}$ reported CES after epidural injection using $60 \mathrm{mg}$ triamcinolone diacetate. Triamcinolone, which was used in our study, can cause spinal cord infarction, which is a complication of intravascular injection to the radicular artery when using transforaminal ESI. ${ }^{27}$ It is considered safe, and no complications, such as spinal cord infarction or lumbosacral nerve-root injury, have been reported when using this particular steroid in CEI.

In addition to local anesthetics, the hyaluronidase was mixed in our study. Hyaluronidase acts to remove barriers between tissues through hydrolyzing glucosaminic bonds between a major intercellular material, hyaluronic acid, and connective tissues to dissolve the bonds. It also relieves fibroplasia in tissues. Hyaluronidase relieves edema and swelling in tissues. ${ }^{28}$ The following should be avoided in patients: 1) hypersensitivity reactions to bovine proteins, 2) infection or swelling, 3) congenital heart defects, and 4) venous congestion. If hyaluronidase use follows recommended methods, there are no serious complications. ${ }^{29}$
There is the second possibility that mechanical compression to the L5 and S1 nerve roots could cause ischemic damage. Chaudhari et $\mathrm{al}^{30}$ reported neurologic complications after epidural injection for spinal stenosis. They considered that local anesthetic-induced edema might compress the nerve roots after epidural injection for spinal stenosis. Usubiaga et $\mathrm{al}^{31}$ reported age-related degeneration causing a decrease in dural membrane elasticity and an increase in epidural pressure. Therefore, epidural injections to patients who are elderly and have severe stenosis or disc herniation may increase mechanical compression, which causes ischemic neurologic damage. In this study, although the patient was not elderly, mechanical compression cannot be ruled out completely. However, a decompression operation was performed 24 hours after symptoms began. It is difficult to think only of the possibility of neurological complications caused by the mechanical compression because of persistent neurologic complications.

\section{Conclusion}

Despite the use of CEI, which is known as a safer method, severe CES occurred in the patient in this study. Several studies have reported transient neurologic complications, but the neurologic complication in our case was persistent severe CES. Therefore, we recommend that clinicians check severe spinal stenosis of the lower lumbar or the lumbosacral level by computerized tomography or MRI. If the patient suffers from severe spinal stenosis, CEI should be performed with caution.

\section{Acknowledgments}

This work was supported by an intramural research grant from Chungbuk National University in 2015. We obtained written permission from the patient to publish this case report and the accompanying images.

\section{Disclosure}

The authors report no conflicts of interest in this work.

\section{References}

1. Hoy D, Bain C, Williams G, et al. A systematic review of the global prevalence of low back pain. Arthritis Rheum. 2012;64(6):2028-2037.

2. Bicket MC, Chakravarthy K, Chang D, Cohen SP. Epidural steroid injections: an updated review on recent trends in safety and complications. Pain Manag. 2015;5(2):129-146.

3. Ogoke BA. Caudal epidural steroid injections. Pain Physician. 2000;3(3):305-312.

4. Cohen SP, Bicket MC, Jamison D, Wilkinson I, Rathmell JP. Epidural steroids: a comprehensive, evidence-based review. Reg Anesth Pain Med. 2013;38(3):175-200.

5. Manchikanti L, Pakanati RR, Pampati V. Comparison of three routes of epidural steroid injections in low back pain. Pain Dig. 1999;9:277-285. 
6. Manchikanti L, Bakhit CE, Pampati V. Role of epidurography in caudal neuroplasty. Pain Dig. 1998;8:277-281.

7. Barham G, Hilton A. Caudal epidural: the accuracy of blind needle placement and the value of a confirmatory epidurogram. Eur Spine J. 2010;19(9):1479-1483.

8. Huntoon MA, Martin DP. Paralysis after transforaminal epidural injection and previous spinal surgery. Reg Anesth Pain Med. 2004;29(5): 494-495.

9. Markey JR, Naseer OB, Bird DJ, Rabito SF, Winnie AP. Transient neurologic symptoms after epidural analgesia. Anesth Analg. 2000;90(2): 437-439.

10. Kim DH, Kim HJ. Cauda equina syndrome following epidural adhesiolysis in a patient with spinal stenosis. J Korean Continence Soc. 2003;7(1) 46-49.

11. Nanjayan SK, Swamy GN, Yallappa S, Bommireddy R. Arachnoiditis following caudal epidural injections for the lumbo-sacral radicular pain. Asian Spine J. 2013;7(4):355-358.

12. Devor M, Govrin-Lippmann R, Raber P. Corticosteroids suppress ectopic neural discharge originating in experimental neuromas. Pain. 1985;22(2):127-137.

13. Hirata F, Schiffmann E, Venkatasubramanian K, Salomon D, Axelrod J. A phospholipase A2 inhibitory protein in rabbit neutrophils induced by glucocorticoids. Proc Natl Acad Sci U SA. 1980;77(5):2533-2536.

14. Colimon FJ, Villalobos FJ. Epidural steroid injections: evidence and technical aspects. Tech Reg Anesth Pain Manag. 2010;14(3): 113-119.

15. Kane RE. Neurologic deficits following epidural or spinal anesthesia. Anesth Analg. 1981;60(3):150-161.

16. Moen V, Dahlgen N, Irestedt L. Severe neurological complications after central neuraxial blockades in Sweden 1990-1999. Anesthesiology. 2004;101(4):950-959.

17. Botwin KP, Gruber RD, Bouchlas CG, et al. Complications of fluoroscopically guided caudal epidural injections. Am J Phys Med Rehabil. 2001;80(6):416-424.

18. Somanchi BV, Mohammad S, Ross R. An unusual complication following caudal epidural steroid injection: a case report. Acta Orthop Belg. 2008;74(5):720-722.
19. Lee MH, Han CS, Lee SH, et al. Motor weakness after caudal epidural injection using the air-acceptance test. Korean J Pain. 2013;26(3):286-290.

20. Kennedy DJ, Dreyfuss P, Aprill CN, Bogduk N. Paraplegia following image-guided transforaminal lumbar spine epidural steroid injection: two case reports. Pain Med. 2009;10(8):1389-1394.

21. Jeong JS, Park KD, Lim OK. A case report of persistent cauda equina syndrome following epidural anesthesia. $J$ Korean Assoc EMG Electrodiagn Med. 2009;11(2):151-155.

22. Bilir A, Gulec S. Cauda equina syndrome after epidural steroid injection: a case report. J Manipulative Physiol Ther. 2006;29(6):492.e1-e3.

23. Loo CC, Irestedt L. Cauda equina syndrome after spinal anaesthesia with hyperbaric 5\% lignocaine: a review of six cases of cauda equina syndrome reported to the Swedish Pharmaceutical Insurance 1993-1997. Acta Anaesthesiol Scand. 1999;43(4):371-379.

24. Drasner K, Rigler ML, Sessler DI, Stoller ML. Cauda equina syndrome following intended epidural anesthesia. Anesthesiology. 1992;77(3):582-585.

25. Robertson JD. Structural alterations in nerve fibers produced by hypotonic and hypertonic solutions. J Biophys Biochem Cytol. 1958;4(4):349-364.

26. Lenoir T, Deloin X, Dauzac C, Rillardon L, Guigui P. Paraplégie secondaire à une infiltration épidurale interlamaire lombaire, à propos d'un cas [Paraplegia after interlaminar epidural steroid injection: a case report]. Rev Chir Orthop Reparatrice Appar Mot. 2008;94(7):697-701. French.

27. McCormick ZL, Cushman D, Marshall B, et al. Pain reduction and repeat injections after transforaminal epidural injection with particulate versus nonparticulate steroid for the treatment of chronic painful lumbosacral radiculopathy. $P M R$. 2016;8(11):1039-1045.

28. Lee KJ, Han SG, Yoon SH, Kim JS, Lee YS. Nerve root block with corticosteroids, hyaluronidase, and local anesthetic in the failed back surgery syndrome. J Korean Pain Soc. 1999;12(2):191-194.

29. Kim SB, Lee KW, Lee JW, Kim MA, Kim BH. The additional effect of hyaluronidase in lumbar interlaminar epidural injection. Ann Rehabil Med. 2011;35(3):405-411.

30. Chaudhari LS, Kop BR, Dhruva AJ. Paraplegia and epidural analgesia. Anaesthesia. 1978;33(8):722-725.

31. Usubiaga JE, Wikinski JA, Usubiaga LE. Epidural pressure and its relation to spread of anesthetic solutions in epidural space. Anesth Analg. 1967;46(4):440-446.

\section{Journal of Pain Research}

\section{Publish your work in this journal}

The Journal of Pain Research is an international, peer reviewed, open access, online journal that welcomes laboratory and clinical findings in the fields of pain research and the prevention and management of pain. Original research, reviews, symposium reports, hypothesis formation and commentaries are all considered for publication

\section{Dovepress}

The manuscript management system is completely online and includes a very quick and fair peer-review system, which is all easy to use. Visit http://www.dovepress.com/testimonials.php to read real quotes from published authors. 